\title{
Forecasting the Monthly Stock of Rice and Corn in the Philippines
}

\author{
Renz G. Pureza ${ }^{1, *}$, Pauline Punit ${ }^{2}$, Mildred Dj. Par ${ }^{1}$, Bernadeth G. Nobles ${ }^{3}$ and Audi B. Oliquio ${ }^{4}$ \\ 1Bagbag National High School, Philippines; renz.pureza@deped.gov.ph, mildred.par@deped.gov.ph \\ 2Bagong Nayon II National High School, Philippines; pauline.punit@deped.gov.ph \\ ${ }^{3}$ College of Education Graduate Studies, Polytechnic University of the Philippines, Philippines; \\ bgnobles_pupcs@yahoo.com \\ ${ }^{4}$ Department of Mathematics and Statistics, College of Science, Polytechnic University of the Philippines, \\ Philippines; aboliquino@pup.edu.ph
}

\begin{abstract}
In this study, the researchers studied the status of rice and corn stocks in the country provided by the Philippines Statistics Authority (PSA) starting from 2000 to 2017. Objective: To provide a forecast for the monthly stock of rice and corn in the country for the next succeeding years. Methods: In this study, the researcher uses parametric univariate time series model, known as Seasonal Autoregressive Integrated Moving Average (SARIMA), a model popularized by Box and Jenkins (1976). Findings: Utilising the SARIMA method, forecast on the rice stock could be provided using the model, SARIMA (3 1 3 ) (1 1 1)12. For corn stock model, SARIMA ( $\left.\begin{array}{llll}4 & 1 & 4\end{array}\right)$ (1 111 1) 12 was used. These two models, resulted to a satisfactory outcomes fitted with its specified series using the past values and evaluation of its patterns. Application: This appropriate solution that would greatly help the country and its government, particularly, the policymakers, in the formulation of economic programs. The agricultural sectors would also benefit from this as they plan and provide food security for every Filipinos by reforming any of its programs to lead a better production of crops, agricultural aspects, and the development of the country's economy.
\end{abstract}

Keywords: Forecasting, Rice Stock, Corn Stock, Agriculture

\section{Introduction}

Philippines is situated in Asia as one of the leading suppliers of rice and corn, which are both considered to be the staple food of most Asian countries. 1,2 Being a tropical country with a high amount of fertile lands and great abundance of natural resources, it also encounters many adversities that imperil the major food supply in the country. Typhoons and floods jeopardize the farms and it affects the amount of locally produced food supply. $\underline{3}$ Thus, it is highly important to stabilize and to secure the stocks of grains, both rice and corn, which in turn, affects the economy. According to the reports of the International Rice Research Institute (IRRI), rice is a staple food for over half the world's population and about $90 \%$ of worldwide rice comes from Asia. $\underline{4}$ Thus, its production has a great impact on the country's economy. Meanwhile, the rice and corn stock of the Philippines is divided into three depositories and these are household, commercial, and NFA.

Based on the report of the previous year, the rice stocks in NFA depositories increased by $69.52 \%$, while the other two depositories decreased by almost $11-33 \%$ according to PSA. .5 Last September 2018, the rice inventory of the country declined by $17.91 \%$ below the previous year level of 1,422.84 thousand metric tons which was an indication that rice stocks remained on a downward trend. Based on the average daily consumption of Filipinos of 32,000 MT, this inventory is just sufficient for 62 days which shows a shortage of rice stocks or having a rice crisis. $\underline{\underline{6}}$

*Author for correspondence 
While rice is the top most important crop in the Philippines, the second most important crop is corn. Corn crop has two varieties, yellow and white, which are both produced in the country. ${ }^{\underline{7}}$ White corn is considered as the more important substitute when there is rice shortage; Meanwhile, yellow corn is the primary source of feeds for animal industry and are commonly used by manufacturers.. As of September 2018 PSA findings, the corn stock inventory was 531.07 thousand tons which was $62.66 \%$ lower than last year's record. $\underline{5}$ Same as the trend or rice stocks inventory, the corn stock inventory was also on a downtrend.

The researchers planned to provide a forecast on the rice and corn stocks for the year 2018-2022. The researchers, therefore, aimed to provide information for the use of government purposes, particularly, the policy makers in the formulation of economic programs, as well as, the agricultural sectors to meet and provide food security for every Filipinos by reforming any of its programs to lead a better production of crops, agricultural aspects, and the development of the country's economy, and to those authorized personnel to make decisions for the betterment of the country regarding the topics discussed in this study. This may also help citizens like farmers or manufacturers for the process of restock for better inventories and better financial aspect.

\subsection{Objective of the Study}

The main purpose of this study is to forecast the inventory of rice and corn stocks through the use of the method identified as Seasonal Autoregressive Integrated Moving Average (SARIMA) through the Box-Jenkins Approach. With the use of SARIMA, rice and corn stocks inventory can be forecasted for the successive years of 2018-2022. Forecasting the stock inventory of rice and corn can improve the crops management of the concerned agencies in the Philippines to lessen importation of rice and corn products.

\subsection{Significance of the Study}

Forecasting rice and corn inventory is useful to guide the distribution of crops in the Philippines. Having a forecast of crops, stock is also in the allocation and importation of such products. More importantly in the Philippines a rice and corn producing country unfortunately it imports

\subsection{Research Paradigm}

Figure 1 above the researchers used the Input-ProcessOutput model as a guide in forecasting the monthly stock of rice and corn in the Philippines. It follows a three-step procedure which includes the input, process, and the output.

The researchers input comprised with the data about the rice and corn monthly stock inventory from year 2000 to 2017.

The process involves the data being subjected to Seasonal Autoregressive Integrated Moving Average (SARIMA) using Box-Jenkins Modelling.

The expected output was the predicted values to be compared with the actual observed and five year forecasted values from 2018 to 2022 .

\subsection{Statement of the Problem}

To achieve the objective of the study, the researchers need to answer the following questions:

1. What is the behavior of the graphs for:

1.1. Rice Stock

1.2. Corn Stock

2. What are the best fitted models that will be used in forecasting the Rice and Corn stock Inventory in the Philippines?

3. What will be the predicted values of each of the Rice and Corn stock inventory?

4. What is the interpretation of the Forecasted Values for the next five years of each two mentioned series?

\subsection{Scope and Limitations}

The study was limited only to the problem posed at the beginning of this research. The researcher limited the crops as rice and corn with monthly stock inventory from year 2000 to 2017. The data were gathered from the Philippine Statistic Authority (PSA).. The study only forecasted the monthly stock inventory for the next five years (2018-2022) through SARIMA modelling.

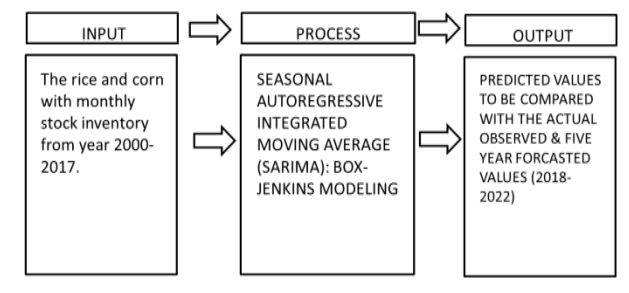

Figure 1. Research paradigm. 


\section{Methodology}

The monthly stock inventory of rice and corn in the Philippines from year 2000 to 2017 were gathered to produce mathematical models using Seasonal Autoregressive Integrated Moving Average (SARIMA) ARIMA ( $\mathrm{p}, \mathrm{d}, \mathrm{q})(\mathrm{P}, \mathrm{D}, \mathrm{Q}) \mathrm{m}$ : the first parenthesis represents the non-seasonal part of the model and the second represents the seasonal part of the model, where $\mathrm{m}=$ number of periods per season. We use uppercase notation for the seasonal parts of the model, and lowercase notation for the non-seasonal parts of the model. The additional seasonal terms are simply multiplied with the non-seasonal terms with the same location and unit using the chosen methods of forecasting: Seasonal Autoregressive Integrated Moving Average (SARIMA) Modelling through a Box-Jerkins Approach.

\subsection{Box-Jenkins Methodology}

Box-Jenkins methodology involves four steps in analyzing time based data. This was a step by step process introduced by the statisticians, George Box and: (i) identification (ii) estimation (iii) diagnostic checking, and (iv) forecasting.

First, the identification step involves the use of techniques to determine the values of $\mathrm{p}, \mathrm{q}$, and $\mathrm{d}$. This is to identify the original series must be transformed to become stationary around its mean and its variance.

Second, the estimation of the model parameters. This involves the tentative models that have been selected. The appropriate order of $\mathrm{p}$ and $\mathrm{q}$ must be specified using autocorrelation and partial autocorrelation functions.

Third, the value of the parameters must be estimated using some non-linear optimisation procedure that minimizes the sum of squares of the errors or some other appropriate loss function.

Diagnostic checking of the model adequacy is required in the fourth step. This procedure is continued until an adequate model is obtained. $\underline{10}$

Finally, the future forecasting generated is to be generated using the minimum mean square error method (Box et al. 1994). SARIMA models are used as benchmark models to compare the performance of the other models developed on the same data set. $\underline{11}$

\subsection{Auto-ARIMA}

Automatic ARIMA forecasting is a method of forecasting values for a single series based on an ARIMA model.
Although EViews provides sophisticated tools for estimating and working with ARIMA models using the familiar equation object, there is considerable value in a quick-and-easy tool for performing this type of forecasting. EViews offers an automatic ARIMA forecasting series procedure that allows the user to quickly determine an appropriate ARIMAX specification and use it to forecast the series into the future. $\underline{12}$

\subsection{Dickey Fuller Test}

If the graph of the rice and corn stock inventory were observed, it is easy to identify whether the data are in stationary or not. To check the stationary status of the data, the researcher has to apply the Augmented DickeyFuller test. The test is significant $\left(p<0.01^{\star}\right)$.

\subsection{Paired T-Test}

The paired sample $t$-test, sometimes called the dependent sample $t$-test, is a statistical procedure used to determine whether the mean difference between two sets of observations is zero. In a paired sample $t$-test, each subject or entity is measured twice, resulting in pairs of observations. Common applications of the paired sample $t$-test include case-control studies or repeated-measures designs. $\underline{13}$

\section{Results and Discussions}

\subsection{Rice Stocks}

The data series patterns presented in Figure 2 exhibit an obvious seasonal recurrence of a pattern. At every 9 th month of the year, the series shows the lowest stock of rice.

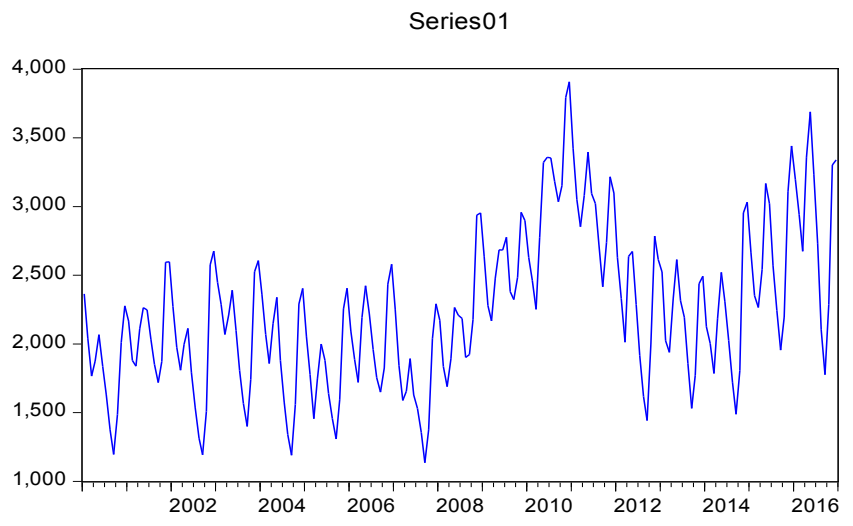

Figure 2. Trends of rice stock inventories in the Philippines (2000-2017). 
This indicates that the total stock in the last three months, specifically: October, November, and December, always have the highest amount of stocks. In this representation of data, September is the month with the lowest stock of rice because few months before this month entail the highest frequency of typhoons in the country which oftentimes affects the stock of root crops and other crops, as well. Meanwhile, the month of December is recorded to obtain the highest stock since farmers do compensate for the lost crops after September.

Table 1 shows the augmented Dickey Fuller test to identify whether the data are stationary or not. Based on the computed $p$-value of ADF test which is equal to 0.0074 , there is enough evidence to reject Ho and conclude that the data series is stationary at level 1 difference.

Figure 3 shows model identification forms the data series of rice stock in year 2000-2017. It is found that the best model to use was ARIMA ( $\left.\begin{array}{lll}3 & 1 & 3\end{array}\right)$ ( $\left.\begin{array}{lll}1 & 1 & 1\end{array}\right)$. The model obtained has a total of $3 \mathrm{AR}$ terms, 12 seasonal AR, and 3 MA terms including the constant. It was having the highest $r$-square value, which is about $85.69 \%$ probability, among the rest of the selection with acceptable Durbin-Watson

Table 1. Dickey-Fuller test

\begin{tabular}{|l|l|l|l|}
\hline \multicolumn{2}{|l|}{} & $t$-Statistic & Prob. $^{*}$ \\
\hline $\begin{array}{l}\text { Augmented Dickey-Fuller test } \\
\text { statistic }\end{array}$ & -3.562618 & 0.0074 \\
\hline \multirow{2}{*}{ Test critical values: } & $1 \%$ level & -3.462901 & \\
\cline { 2 - 4 } & $5 \%$ level & -2.875752 & \\
\cline { 2 - 4 } & $10 \%$ level & -2.574423 & \\
\hline
\end{tabular}

Null hypothesis: D(RICE) has a unit root.

Exogenous: constant.

Lag length: 13 (automatic - based on SIC, maxlag = 14).

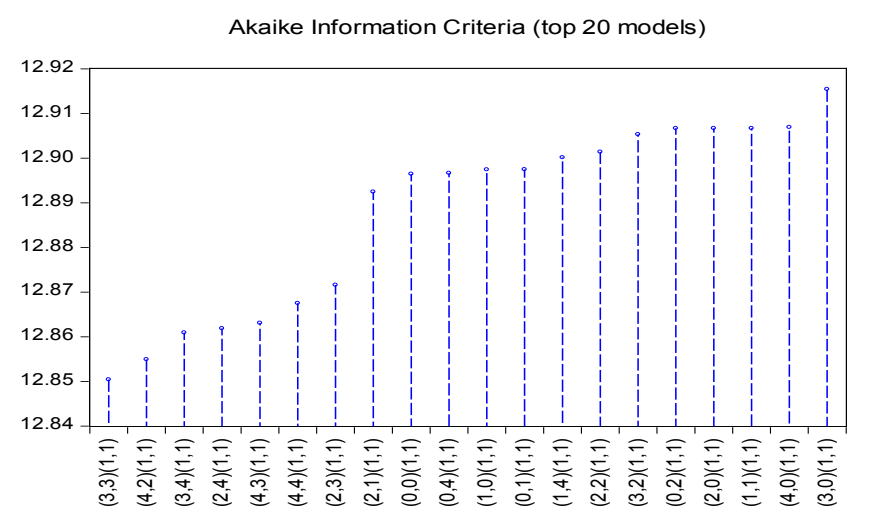

Figure 3. Top 20 models based on Akaike Information Criteria (AIC). test Statistics, invertible Moving Average processes, and stationary Autoregressive processes. The model will be SARIMA ( $\left.\begin{array}{lll}3 & 1 & 3\end{array}\right)\left(\begin{array}{lll}1 & 1 & 1\end{array}\right) 12$, by which will be used in forecasting the actual series.

This indicates that there might be no significant difference between the expected values from the observed values of the rice stock is shown in Figure 4. To test this assumption, paired $t$-test was performed to statistically infer that the two compared series have not much of a difference with each other. Paired $t$-test resulted to a 0.278556 probability value which indicates the acceptance of the null hypothesis. This implies that there is no significant difference between the compared values. Thus, it can be said that the model actually fits within the data series. Hence, in Figure 2, the forecasted values indicate a plotted graph that follows the same trend component, an upward direction of the line, where the line wavers on the same seasonal component vigorously. It shows an upsurge value at every 12 th month of the year. However, it seems that the line reduces its variation year after year. This indicates that the model could effectively forecast for the needed stocks in the succeeding years and therefore, it suggests a fairly effective forecast for predicting the data series.

\subsection{Corn Stock}

Differencing the series, the values are distributed. It indicates that the negative values acquire the same distribution with the positive values. Therefore, it means that the different logarithmic series are nearly equated with a zero mean value. Meanwhile, the correlogram of the data series has reduced its significant level, making more significant spikes on the left side of the plotted

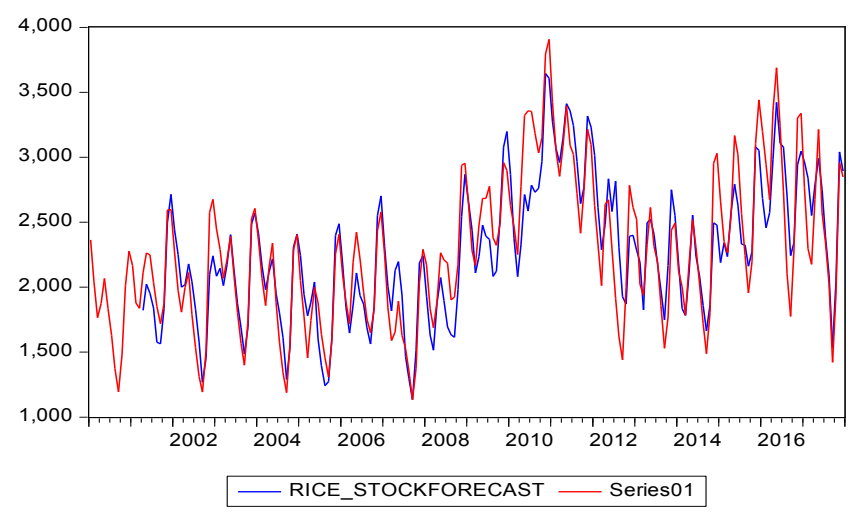

Figure 4. Static forecasting of the rice stock inventory series. 
autocorrelation. The correlogram also implies that there still might be a presence of seasonality within the series given that both autocorrelation and partial autocorrelation have significant spikes on the 12th lags.

Table 2 shows the augmented Dickey Fuller test to identify whether the data are stationary or not. Based on the computed $p$-value of $\mathrm{ADF}$ test which is equal to 0.0000 , there is enough evidence to reject Ho and conclude that the data series is stationary at level 1 difference.

Figure 5 shows the 6 model identification form the data series of rice stock in year 2000-2017. It is found that the best model to use was ARIMA ( $\left(\begin{array}{lll}4 & 1 & 4\end{array}\right)\left(\begin{array}{lll}1 & 1 & 1\end{array}\right)$. The model obtained has a total of 4 AR terms, 12 seasonal AR, and $4 \mathrm{MA}$ terms including the constant. It got the highest $r$-square value, which was about $47.31 \%$ probability, among the rest of the selection with acceptable DurbinWatson test Statistics, invertible Moving Average processes, and stationary Autoregressive processes. The model SARIMA (4 14 ) (1 11 ll) 12, by which will be used in forecasting the actual series.

This indicates that there might be no significant difference between the expected values and the observed

Table 2. Dickey-Fuller test

\begin{tabular}{|l|l|l|l|}
\hline \multicolumn{2}{|l|}{} & $t$-Statistic & Prob. $^{*}$ \\
\hline $\begin{array}{l}\text { Augmented Dickey-Fuller test } \\
\text { statistic }\end{array}$ & -16.87349 & 0.0000 \\
\hline \multirow{2}{*}{ Test critical values: } & $1 \%$ level & -3.461178 & \\
\cline { 2 - 4 } & $5 \%$ level & -2.874997 & \\
\cline { 2 - 4 } & $10 \%$ level & -2.574019 & \\
\hline
\end{tabular}

Null hypothesis: $\mathrm{D}(\mathrm{CORN})$ has a unit root.

Exogenous: constant.

Lag length: 2 (automatic - based on SIC, maxlag $=14$ ).

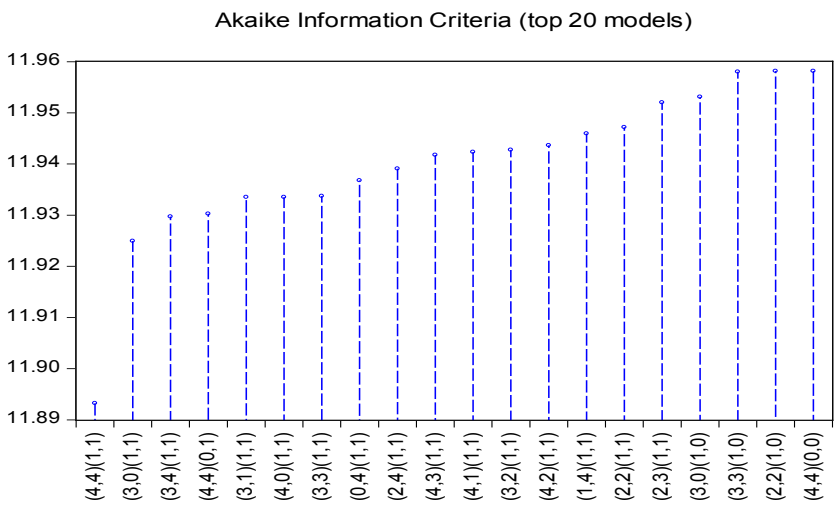

Figure 5. Top 20 models based on Akaike Information Criteria (AIC). values of the Corn stock is shown in Figure 6. To test this assumption, paired $t$-test was performed to statistically infer that the two compared series have not much of a difference with each other. Paired $t$-test resulted to a 0.277914 probability value which indicates the acceptance of the null hypothesis. This implies that there is no significant difference between the compared values. Thus, it can be said that the model actually fits the data series. Hence, in Figure 7, the forecasted values indicate a plotted graph that follows the same trend component, an upward direction of the line, where the line wavers on the same seasonal component vigorously.

\section{Conclusions}

The study submits to the models of the rice and corn stock to be used in forecasting the two data series. Coming up with these models through SARIMA method, the investigators obtained the first model, for the Rice stock

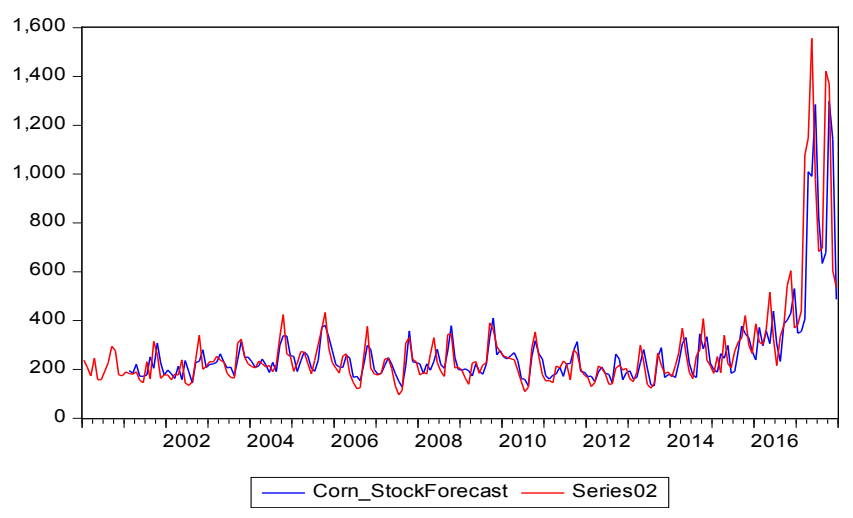

Figure 6. Static forecasting of the corn stock inventory series.

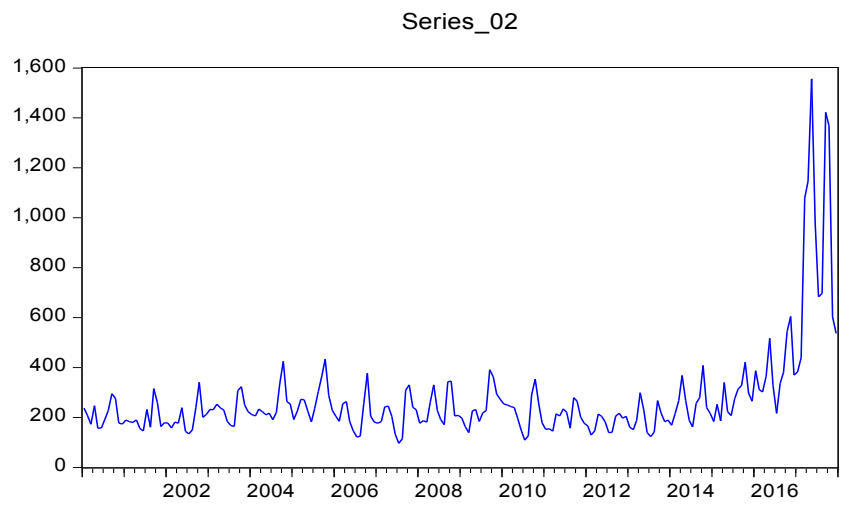

Figure 7. Trends of corn stock inventories in the Philippines (2000-2017). 
which is SARIMA ( $\left.\begin{array}{lll}3 & 1 & 3\end{array}\right)\left(\begin{array}{lll}1 & 1 & 1\end{array}\right) 12$ and the second model, for the Corn stock, SARIMA (4 14 l $)\left(\begin{array}{lll}1 & 1 & 1\end{array}\right)$ 12. The corn stock predicted values, as well as, the predicted values of the rice stock, were statistically inferred and that, there were no significant differences with their particular actual observed values.

\section{Recommendations}

Results show that the two models have satisfactorily fitted their specified series and satisfied the diagnostic checking for the models. The static forecasted values of both series were following the trend pattern of the past values of their allotted observed values which were going on an upward direction indicating favorable outcome for the study. Showing results that are favourable enough, such as having the expected future values on both observations to continue to rise up time after time, the investigators suggest furthering including the actual observed values in the near future to be compared with the forecasted values of the rice and corn stock in the study. This may even be of use for the decision making that the government has to make in the future instances, to make the possible changes and reforms for any possible improvement of the stock of both corn and rice.

\section{References}

1. Why is there a rice crisis in the Philippines? [cited $2016 \mathrm{Dec}$ 28]. http://cnnphilippines.com/business/2018/09/07/ricecrisis-explainer.html.

2. Forecasting the quarterly production of rice and corn in the Philippines: a time series analysis. [cited 2017]. https://iopscience.iop.org/article/10.1088/1742-6596/ 820/1/012007.

3. Typhoon decimates rice crop in Philippines. [cited 2018 Dec 28]. https://www.npr.org/2018/09/20/649779338/ typhoon-decimates-rice-crop-in-philippines.

4. Philippine Journal of Development. Policy options for rice and corn farmers in the face of seasonal climate variability. [cited 2018 Dec 18]. https://dirp3.pids.gov.ph/ris/pjd/ pidspjd09-1ricecornfarmers.pdf.

5. Rice and corn stocks in the Philippines. [cited 2016]. http://www.fao.org/fileadmin/templates/rap/files/ meetings/2016/161109_AMIS_3.7-Rice__Corn_Stocks_ in_the_Phil_08Nov2016.pdf.

6. Why does the Philippines import rice: a solution to the rice shortage. [cited 2018 Jul 14]. https:/www.nodai.ac.jp/cip/ iss/english/9th_iss/fullpaper/1-1-5nchu-tibao.pdf.

7. White corn in the Philippines: contaminated with genetically modified corn varieties. [cited 2018 Jun 06]. http://www.greenpeace.org/seasia/ph/PageFiles/566478/ White-Corn-In-The-Philippines.pdf.

8. Maize in the Philippines: production systems, constraints, and research priorities. [cited 2004]. file://C:/Users/a/ Downloads/mp04ge01\%20(1).pdf.

9. Rice and corn stock inventories. [cited 2018]. https://psa. gov.ph/content/rice-and-corn-stocks-inventory- 0 .

10. Time series analysis forecasting and control. 4 th ed. [cited 2013 May]. https://www.wiley.com/en-us/Time+Series+ ontrol\%2C+4th+Edition-p-9781118619193.

11. Seasonal ARIMA models. [cited 2018]. https://otexts.com/ fpp2/seasonal-arima.html.

12. EViews 11 help topics. [cited 2018]. http://www.eviews. com/help/helpintro.html\#page/content\%2Fhelpintro.html.

13. ModellingandforecastingtheexchangerateofthePhilippines: a time series analysis. [cited 2015 Jul]. https://www. researchgate.net/publication/280098546_MODELLING_ AND_FORECASTING_THE_EXCHANGE_RATE_OF_ THE_PHILIPPINES_A_TIME_SERIES_ANALYSIS 